\title{
Work-life balance and organizational commitment: a study of field level administration in Bangladesh
}

\section{Introduction}

Majority of research on work-life balance (hereafter WLB) in the public sector is conducted in Anglo-Saxon context. When some of these findings are applied to understand the WLB in other cultures, it can be problematic especially in cultures where a dual-earner labour force is not popular (Chandra, 2012). For example, American and European companies have fewer working hours, more established policies of flexi-working hours and more generous parental leave than eastern countries (Chandra, 2012). Sometimes the implication of WLB policies can be challenged by local cultures (Lewis, Gambles and Rapoport, 2007). With the globalization and people movement, many western originated HRM practices are adopted in Bangladesh. WLB becomes one of the areas the country endeavours to improve through regulations, such as increasing maternity leave from four months to six months in 2011 and providing 15 days of paternity leave for men working in public sectors. However, very few studies have examined WLB in Bangladesh. Up to now only four research about WLB has been carried out in Bangladesh (e.g. Hossen, Begum, \& Zhixia, 2018; Hussain \& Endut, 2018; Tasnim, Hossain, \& Enam, 2017) and these studies are based in the private sector. Research in the field of public administration has long pointed out that some HRM practices (e.g. motivation and organizational commitment) are perceived differently in the public sector compared to the private sector (Gould-Williams et al., 2014).

This study assesses the antecedents of WLB among the Bangladesh Civil service administration cadre officers who are a vital tier in the public sector of Bangladesh. These officers perform multiple tasks and have a constantly high workload (Huque, 2011). Also, 
women increasingly joining the workforce, many organizations realized the urgency of providing, formally and informally, support to employees to managing work and life to improve organizational productivity (Hossen, Begum and Zhixia, 2018). This study proposes job stress and workplace support as antecedents of WLB like many other existing studies (Mauno and Kinnunen, 1999; Roberts, 2007; Bell, Rajendran and Theiler, 2012). Many existing studies suggest that WLB is an explanatory factor for employee retention, talent management, employees' attitude toward work and organizational performance (Deery, 2008; Bell, Rajendran and Theiler, 2012; Sung Kim and Ryu, 2017). Working as a civil servant is the most secure job in Bangladesh (Siddiquee, 2003). Because of this high job security, recruitment of civil servants often attracts highly educated and skilled candidate (Huque, 2011). In consideration of that human commitment plays a detrimental role in success of organizations; this study will explore the impact of WLB on affective organizational commitment.

By exploring WLB in the public sector of Bangladesh, this study extends our knowledge of WLB in the developing countries. It also provides opportunities for researchers and practitioners to understand the application of WLB in Bangladesh. Especially, the study could provide some insights for policy makers in Bangladesh and other similar developing countries to reform their WLB related HRM practice.

\section{WLB: The Spillover Theory Perspective}

WLB can be considered as the degree to which an individual can simultaneously balance the emotional, behavioural and time demand of both paid work and personal life (Hammer et al., 2005). This study applies the 'spillover theory' underpin the importance and implications of WLB in the field administration of Bangladesh. Spillover theory relates the transition about how one's attitudes, emotion, behaviour produced either at workplace or personal life can influence the other domains of life In this regard, work-family spillover has been described by 
Edwards \& Rothbard (2000) as the mutual influence of work and family on each other, which produces the identical complementarities between. the two domains. However, Carlson, Kacmar, \& Williams, (2000) opines that the very nature of work-family spillover tends to be behavioural or affective. When the workplace attitudes and moods are carried to home and vice versa, it is generally identified as affective work-family spillover.

The effect of the spillover can be both positive and negative and it can flow in both directions: work to personal life or personal life to work (Hill et al. 2001). Positive spillover leaves a beneficial impact as it deals with the transfer of positively balanced skill, behaviour and values from one domain to another and thereby enriches or jeopardizes the receiving domain (Hanson, Hammer and Colton 2006). The findings of the study of Hammer et al. (2005) demonstrate that increases in positive work-family spillover, particularly family-to-work positive spillover, are related to the decrease in depression of an employee. In contrast, the negative spillover has detrimental effect on the employees' personal life and organizational outcomes. Finnish dual-earner couples leads to psychological distress and lower job and life satisfaction (Mauno and Kinnunen, 1999). In fact, 'more ecological barriers would be associated with more negative spillover between work and family'(Grzywacz \& Marks, 2000, pp.120).

\section{Role of administration cadre officers}

In public sector, the Bangladesh Civil Service (BCS) plays a pivotal role in fostering the development activities of the government in its all tiers. Among the 28 different cadre officers recruited through Bangladesh Public Service Commission, Administration cadre officers work both in the ministries and field level offices (see the figure 1). The career pattern and professional duties and responsibilities of the field administration in Bangladesh have been vital in respect to growing socio-economic development, industrialization and rapid growth of information technology (Uddin et al. 2015). The Bangladesh Civil Service (Administration) 
cadre has to accomplish the task of implementing the government policies at the field level. These officers have roles being mangers and coordinators in field administration. On top of that, the officers have other regular duties such as revenue and land management, magisterial duties, conducting elections, disaster management, poverty alleviation, and implementation of equitable and the pro-poor safety net (Jacobs 2009) programs of the government at the grass root level. Eventually, the long working hours, excessive work pressure, working at the weekends and holidays have become a take-for-granted matter in field administration (Huque 2011). The multiplicity of tasks, high load of work in field administration (Huque 2011) affects the balance of the work and non-work life of the officers.

Insert Figure 1 about here

\section{Antecedents of WLB}

\section{Job stress}

Job-related stress as a mismatch between the employee and the workplace environment (Beehr, Farmer, Glazer, Gudanowski and Nair 2003). Stress usually occurs if and when this mismatch jeopardizes an employee's well-being. Regarding the source of job-related stress, Hsiao and Barak (2013) posit that heavy work load, unfavourable working environment, speedy and repetitive job, complicacy of the task and time constraints are some potential job stressors. White, Hill, McGovern, Mills, \& Smeaton (2003) argue that the work pressure derived from intense work demands may bring the negative physiological outcomes such as fatigue and exhaustion which ultimately leaves impact on the WLB. 
The inter-link between WLB and job-related stress has been dealt in many studies. Byron (2005) suggested that a consistent relation exists between job-related stress and worklife conflict which is in fact the absence of WLB. Evidence justifies that the excessive work load, a vital source of job-related stress, is the most relevant antecedent of work-life conflict (Major, Klein, \& Ehrhart 2002). Likewise, Hsiao and Barak (2013) indicate that the unbalanced work and life a prime outcome of stress that an employee undergoes either in the work domain, in personal life or in both.

Public-sector employees encounter job-related stress from multiple sources since their activities affect different stakeholders such as citizens, government, colleagues, subordinates and their personal and family life (McHugh and Brennan, 1994). A continuous exposure to these multiple source of job stressors may lead to physical ill-being, absenteeism and low job performance (McHugh and Brennan, 1994). All these problems are thought to have substantial influences on an individual's WLB. Goddard, O'Brien and Goddard (2006) suggested that environments with pressure at work have a significant link with employees' burnout, reduced job satisfaction and absence of WLB. Based on the review of literature on WLB and job stress, we have the following hypothesis.

\section{H1: High levels of job pressure stress are associated with low levels of WLB.}

\section{Workplace Support}

Workplace support is defined as the degree to which individuals perceive that their well-being is being looked after by workplace sources (Kossek et al. 2011). Modern organizations provide both general and content specific workplace support. A plethora of WLB literature (e.g. Behson 2005; Frone, Yardley and Markel 1997; Chiang et al. 2010;) recognize that workplace social support can be manifested through some formal and informal means such as family supportive policies and culture and supportive supervisors' attitudes. This kind of supportive organizational actions play a crucial role in employees' WLB. Thomas and Ganster (1995) 
categorize the family supportive organizational effort into two major components: family supportive organizational policies and supervisor work-family support. Apart from these two components, family supportive co-worker behaviour also plays an important role in ensuring a family supportive work environment (Babin and Boles, 1996).

Family supportive organizational policies are a vital factor for employees to achieve WLB (Hobson, Delunas and Kesic 2001). Formally, organizations adopt various family friendly programs such as flexible working practices, family leave options such as maternity and paternity leave and child care assistance, on-site or off-site day care facilities and many other forms (Chiang et al. 2010). These benevolent programs have been regarded as boundary spanning resources since these programs cross a line between the interface between work and family (Voydanoff 2004). The gradual increase of flexible working policies is a common practice in organizational settings (CIPD 2018). Eventually, the organizations which believe in people as assets in business management are prone to adopt these humane initiatives to bring WLB for its people.

Next, family supportive supervisor behaviour implies that supervisors provide informal help at resolving work family conflict and balancing work and non-work commitments (Kossek et al. 2011). The family supportive programs are being introduced at a growing rate and the proper implementation of these programs largely depends on the discretion of supervisor because it is the supervisor who has a direct influence on the employees regarding their work load and job-related stress (Beehr et al. 2003). If a supervisor turns to be truly family responsive, employees will feel at ease to enjoy a relatively better-balanced work and life. Family responsive informal supervisor behaviour tends to be more effective compared to the formal work place family supportive policies (Behson 2005; Kossek and Nichol 2006). Likewise, several other studies (Frone, Yardley and Markel 1997; Thomas \& Ganster 1995; Thompson and Prottas 2006) emphasize that family supportive supervisors' support is associated with 
lower levels of employee work-family conflict. For examples, the studies (Anderson, Coffey and Byerly 2002; Frone, Russell and Cooper 1997) indicate that employees who get more supervisor support in the work place undergo less work-family conflict. Furthermore, higher level of work-family positive spillover is significantly related to a higher level of supervisor support since family responsive supervisors act a resource to employees (Thompson and Prottas 2006). Hammer et al. (2009) asserts that family responsive supervisor behaviour is associated with the work-family balance, work-family positive spill over and job satisfaction compared to the outcome of general supervisor support.

Last, a supportive work environment is characterized by the employee perception that co-workers are highly involved and supportive (Babin and Boles 1996). An individual's relationship with other colleagues can have an important influence on resolving work-family conflict (Frone et al. 1996). Since several studies (Shinn, Wong, Simko \& Ortiz-Torres 1989; Ladd \& Henry 2000) established the positive correlation between co-worker support, organizational support and supervisor support, it is expected that family supportive co-worker behaviour may have some positive influence on the WLB. A supportive co-worker can create a congenial working environment encouraging employees to help each other at meeting family demands. A group of female police officer in Tremblay et al. (2011)'s study stated that colleagues' support at work can facilitate each other redistribute work task in order to balance both work and life demands informally in short term. It is worth of being aware of that social pressure from co-workers also might impede the usage of work-life initiatives when resources are stretched (Kirby \& Krone 2002). Based on the reviewed literature on workplace support and its different aspects, we have the following hypotheses:

$\mathrm{H}_{2}:$ High levels of family supportive organizational policy are associated with high levels of WLB. 
H3: High levels of family supportive supervisors' behaviour are associated with high levels of WLB.

H4: High level of family supportive coworkers' behaviour is associated with high level of WLB.

\section{Outcome of work-life balance: employees' affective commitment}

Employee commitment is defined as 'the relative strength of an individual's identification with, involvement in and loyalty to a particular organization' (Porter, Steers, Mowday, \& Boulian, 1974, p. 604). Among the three types of commitment identified by Meyer, Allen, \& Smith (1993) affective commitment (employees' emotional attachment to organizations ) has been often found to be consistently and negatively associated with worklife conflict ( Agarwala et al. 2014). Employees would be able to balance their work and life when they have enough resource (e.g. time, managerial support and family-friendly policies). Consequently, they would emotionally commit to their organizations. However, majority of the studies on organizational commitment are based on the private sector. Public organization management studies (e.g. Kim and Ryu,2017; Gould-Williams et al. 2014, Homberg and Vogel 2016) shows that employees in the public sector and private sector are motivated in different ways. Specially, employees in the public sector are altruistically motivated to serve the interests of communities; employees in private sector are motivated by extrinsic reward (Kim and Ryu, 2017). Hence, it is not known if job stress would lead to less balanced work and life in a Bangladesh, so reducing employee commitment.

Current studies on WLB and employee commitment find that a high level of WLB is associated with a high level of affective commitment (e.g. Agarwala et al., 2014; Choi et al., 2018; Wayne, Casper, \& Allen, 2017). According to social exchange theory, the relationship between employers and employees is reciprocal. When employees feel they have been cared by their organizations through formal family supportive policy and informal family supportive 
initiatives from colleagues and supervisors, employees tend to reciprocate the care with their emotional commitment to the organizations (Agarwala et al. 2014). The positive relationship between WLB and organizational commitment seems is not influenced by national cultural differences (Agarwala et al., 2014; Choi et al., 2018; Wayne, Casper, \& Allen, 2017). Hence, we have the following hypothesis.

$H_{5}$ : work-life balance is positively related to affective commitment.

Figure 2 summarizes the hypothesized relations

Insert Figure 2 about here

\section{Method}

\section{Data collection}

A structured questionnaire in English was used for this study as English is prevalent in Bangladesh especially among the government officers. For administrative purpose, Bangladesh is divided into Divisions, districts and sub-districts (Upazila). These three tiers of the field administration are headed by the officers of BCS (Administration) cadre with the designation of Commissioner, Deputy Commissioner, and Upazila Nirbahi Officer ${ }^{1}$. Currently 563 officers are working in the above mentioned three designations and they are the population of this study (MOPA 2017). A web-link administered questionnaire was sent directly to the target

\footnotetext{
${ }^{1}$ Upazila Nirbahi Officer is the Chief Executive Officer of a sub-district (Upazila) in Bangladesh.
} 
population of the study through emails. 159 officers participated in the study, but two of them did not complete the survey. This makes the usable data 157 with the response rate $28 \% .81 \%$ of respondents are male. The percentage of females taking part of this study seems low, but it is $9 \%$ higher than the proportion of females working as BCS officers (United Nations Development Programme, 2012). $75.8 \%$ of respondents have worked in the organization more than five years. The majority (76.5\%) of respondents have children below 17 years old. The mean age of the participants is 35 .

\section{Measures}

This research used ' $W L B$ ' as a dependent variable and Job Pressure Stress, family support policy, family supportive supervisors' behaviour and family supportive coworkers' behaviour as independent variables. We controlled Gender, Marital status, Age and Service Tenure as these variables are often included in the studies of WLB (e.g. Cegarra-Leiva et al. 2012). All the measures are rated on a five point-Likert scale, ranging from $1=$ strongly disagree to $5=$ strongly agree.

WLB was measured by four items from Bell, Rajendran \& Theiler (2012), a sample item is ' It is easy for me to balance the demands of my work and personal life', Job stress was measured by seven items from Stanton et al. (2001). Work place support is measured by 11 items which contains three factors, family supportive organizational policies, family supportive supervisors' behaviour, family supportive co-workers' behaviour (Banu and Duraipandian, 2014). We measured affective organizational commitment with Meyer and Allen's (1991) five items.

\section{Reliability of the variables}

Existing scales were used to measure the variables, but we still carried out reliability test considering that these scales were used in a different cultural context. The result shows that majority of scales met the often-referenced threshold for internal consistency (Cronbach alpha 
$=0.7$ ), but Cronbach alpha for job stress is 0.66 ; for family support policy is 0.69 . Considering that these two variables' Cronbach alpha is close to the threshold, we decided to keep all the items instead of deleting some of items to increase the Cronbach alpha. Another reason why we kept all the items is because measures with Cronbach alpha over 0.60 considered to be reliable (DeVellis, 2012). The Cronbach alpha for the two-item measured family coworkers' supportive behaviour is 0.52 . We did not consider this scale has reliability issues as Nannally (1978) pointed out that Cronbach alpha is heavily dependent on the number of items composing the scale.

\section{Results}

\section{Descriptive information}

Table 1 explains the mean and standard deviation of each variable and the correlations among the variables. Among the control variables, Male workers found it more challenging to balance work than females $(r=-.17, \mathrm{p}<0.01)$. Other remaining control variables do not show any significant correlation with WLB. The table also shows that the dependent variable WLB has a significant negative correlation with job pressure stress $(r=-.47, \mathrm{p}<0.01)$. The mean of job stress is 4.15 , which indicates that participants consider their jobs are highly stressful. As expected, all the three elements of work support are positively and significantly related to WLB. Interestingly, the result here shows that affective organizational commitment is not statistically related to work-life balance and job stress, but it is significantly and positively related to the three types of workplace family support.

Insert Table 1 about here 


\section{Testing the hypotheses}

The results of multiple regression analyses are presented in Table 2. In Table 2, model 1 only includes control variables. Model 1 shows that age is positively and significantly related to WLB $(\beta=0.05, p<0.05)$. That means people get better at balancing work and life when they get older. As for people with childcare responsibilities, they experience more imbalance between work and life than people without caring young children $(B=-.36, p<.05)$. The result also shows that male cadre officers' work and life is not as balanced as their female colleagues $(B=-.41, \mathrm{p}<.01)$. The control variables contribute $10 \%$ of the variance in WLB.

Model 2 includes the main predictors, namely job pressure stress, family supportive organizational policy, family supportive supervisor behaviour and family supportive co-worker behaviour. The result shows that job pressure stress is negatively and significantly related to WLB $(\beta=-0.62, p<0.05)$. Therefore, the hypothesis $\mathrm{H}_{1}$ is supported.

The result also indicates that family supportive organizational policies have the most influential power on these officers' WLB in comparison with colleagues and supervisors' support behaviour $(\beta=0.22 ; P<0.05)$. Colleagues' and supervisors' family supportive behaviour do not have statistically significant influence on these cadre officers' WLB. In addition, work-life balance has a positive influence on affective organizational commitment, but this relationship is not significant $\left(B=0.09, p=0.15\right.$ ). Hence, $\mathrm{H}_{2}$ is supported, but $\mathrm{H}_{3}$ and $\mathrm{H}_{4}, \mathrm{H}_{5}$ are not supported in this study.

Insert Table 2 


\section{Discussion}

The finding shows the older the people get, the better the WLB they experience. The majority of our respondents are mid-life employees at the age of 30-40. At home, this group of people face the challenges of caring for young children. At work, their career is also getting established and they experience increased responsibilities. This group of people are belong to generation Y who do not believe job security and values WLB (Cogin, 2012). They perceive work and life are equally important, so they will be more aware of the effect of work on their personal life. Multiple responsibilities among younger generations are the reasons why people get better at balancing their WLB as they get older. The similar kind of findings are evident in the study of Lewis et al., (2007) where indicated that younger generations are more worried about WLB more than the previous generations.

We also find female participants have better WLB than males working as BCS officers in Bangladesh. This finding is contradictory to most of the WLB literatures which often found that female generally have more difficulty reconciling work and family life (e.g. Hill et al. 2001; Byron 2005, Tasnim, Hossain and Enam 2017). One reason is that most of these studies are conducted in western countries where there are different family structures and social institutions (Chandra 2012). In the public sector of Bangladesh, females only take up 10\% of BCS officer roles. Our data of female participants is $19 \%$, which is overrepresented, but we still need to interpret the result with caution as a single study dealing with a small number of female responses may not represent the actual scenario of the female officers' WLB in the field administration in Bangladesh, therefore, more in-depth studies would reveal a comprehensive picture of the female's WLB in the public sector. Moreover, With the encouragement of government policies on gender equality, the number of females join the workforce has been increasing every year (UNDP, 2012). This also means males have to take more responsibilities at home than the traditional roles they used to play domestically. This could have contributed 
to the reason why males have negative perceptions at work and life balance if they are not used to the new roles at home.

This study also shows that people with childcare feel that they are less balanced between work and life than their peers without child caring responsibilities. This finding is consistent with many previous studies which suggest childcare as a vital factor influencing people's WLB (e.g. Hill et al. 2001, Smith and Gardner 2007). In Bangladesh, it is social expectation that females should care the children and males are considered not being manly to take childcare tasks (Jesmin and Seward, 2011). Though 15-day-paternity leave is legislated in Bangladesh in 2011, due to stereotypical view on division of childcare between genders, males may not take the full leave. Also, on-site day care or childcare facilities in the work place are very limited, which makes the child care challenging for employees. With increasing number of females gaining education and entering job market, sharing child-caring responsibility can become a conflict at home (Akter 2016). As a result, this conflict could spill to workplace and cause work-life imbalance. The government should consider providing support to employees to reduce the stress caused by multiple roles. For example, providing child or elderly cares can ease the demand of family roles. A satisfactory family life can indirectly create a positive emotional feeling for employed parents at workplace (Kulik, Shilo-Levin and Liberman, 2015). Therefore, this finding suggests the need of the paternity leave and on-site childcare for the parents with caring children in the Bangladesh Civil Service.

In terms of job stress, the result shows the officers felt their job is highly stressful. This high job stress was significant contributor to their imbalanced work and life. This also is the case in some previous research (e.g. Cavanaugh et al. 2000, White et al. 2003). Therefore, the increase in job stress substantially reduces the BCS officers' WLB in Bangladesh. White et al (2003) holds that job stress brings negative psychological outcomes such as fatigue, anxiety and other health related problems. The pressure originated from the multiple kinds of duties in 
field administration need to be addressed with due care. Therefore, the findings uphold the need for adequate balance of work and non-work activities. Hence, it can be suggested that job stress can be reduced through some initiatives such as provision for annual leaves, segregation from work in the weekends and holidays, changing the culture of working in evenings.

This finding suggests that WLB can be enhanced by formulating government's family supportive policies. Though supervisor and co-worker supportive behaviour was positively related to WLB, the associations were not significant. This finding appears to be contradictory to the related studies (Chiang et al. 2010; Grover and Crooker 1995; Clutterbuck 2003; Anderson Coffey and Byerly 2002; Frone, Rusell and Cooper 1997). Most of the previous studies are conducted in the context of the private sector while the present study exclusively deals with the public sector since the respondents represent the public sector of Bangladesh, specifically the Civil Service of Bangladesh. The distinction between public sector and private sector is quite obvious because of a different set of attributes which distinguish one from the others (Rainey 1982). One public study at an Austrian regional university also indicates that supervisors and peers support is not sufficient to deal with work and life conflict (Samad, Reaburn, Milia, 2015). Allen et al. (2014) research also pointed out that family-related government policies are critical for working parents to achieve work and life balance. Allen et al. (2014) also posit that family-supportive supervisors can strengthen the positive relationship between family-related policy and WLB. It seems like the role of supervisors becomes influential provided that organizations have policies to encourage employees to balance work and life.

The study shows that WLB is positively related to affective organizational commitment, but this is not significantly associated like the findings from many existing research (e.g. Agarwala et al. 2014; Choi et al. 2018; Kim and Ryu, 2017;). This counter-intuitive result suggests that WLB is not a strong predictor of these officers' commitment. We speculate that 
longer hours are inevitable considering the multiple roles the Cadre officers play and the unavoidable pressures placed by the top/local government organizations. This would have impact on WLB, but people working in the public sector have strong public motivation to serve people, even sacrifices their personal need to meet the job demand (Gould-Williams et al., 2014). Hence, their affective commitment to their job is not influenced by job stress and WLB under the buffer of public motivation. However, the interpretation of our finding is limited by the nature of single time-point and cross-sectional data. A future study with longitudinal data and an additional variable of public motivation would shed more light on the causal relationship between WLB and affective commitment.

\section{Limitations}

One of the limitations of the study is that we did not explore whether family supportive organizational policies exist or not. Instead, we focused on the perceptions of family support. Future studies should investigate if the organization has policies to help civil servants to balance their work and life. If it has policies, whether it is promoted in organizations to encourage employees to use them, or barriers exist in organizations to prevent employees from benefiting from those policies.

Another limitation of the study is that the data are inclusively from one organization. The benefit of this kind of data is to provide a collective view of the WLB in this organization, which serves a good vantage point for understanding WLB in the public sector of Bangladesh. However, the generalizability is limited by this kind of data. Future studies should endeavour to collect data from various public organizations in Bangladesh to have a more holistic view.

\section{Conclusion}

This study has important theoretical and practical implications. First, this study provides an exploratory study at understanding of WLB in an Asian country, Bangladesh. With data from 
the field administration of Bangladesh, our finding suggests that the job stress and family supportive organizational policies are significant predictors of WLB. Despite of the high job pressure the officers experience and the inceptive stage of WLB practice in the country, these officers' affective organizational commitment is not tainted. This deviated from the current literature of WLB based at western context. This indicates that different cultural and institutional factors could influence individuals' perspectives at WLB. This paper also has important implications for government policy makers and other organizations in Bangladesh. This study indicates that job stress and role conflict can have negatively impact on Civil servants' WLB. This finding suggests that government policy makers in Bangladesh should consider legalizing employee-friendly policies to improve WLB among workers in general. 


\section{Reference:}

Anderson, S., Coffey, B. and Byerly, R. (2002), "Formal Organizational Initiatives and Informal Workplace Practices: Links to Work-Family Conflict and Job-Related Outcomes", Journal of Management, 28(6), 787-810.

Agarwala, T. et al. (2014) "Influence of managerial support on work-life conflict and organizational commitment: an international comparison for India, Peru and Spain", International Journal of Human Resource Management, 25(10), pp. 1460-1483.

Akter, K. (2016) "work-life balance strategies and consequences- a few aspects", ASA University Review, 10(1), pp. 35-52.

Babin, B. and Boles, J. (1996). "The effects of perceived co-worker involvement and supervisor support on service provider role stress, performance and job satisfaction", Journal of Retailing, 72(1), 57-75.

Banu, A. R., \& Duraipandian, K. (2014). "Development of an Instrument To Measure Work

Life Balance of It Professionals in Chennai", International Journal of Management, 5(11): 976-6502.

Beehr, T., Farmer, S., Glazer, S., Gudanowski, D. and Nair, V. (2003), "The enigma of social support and occupational stress: Source congruence and gender role effects", Journal of Occupational Health Psychology, 8(3), 220-231.

Behson, S.(2005), "The relative contribution of formal and informal organizational work family support', Journal of Vocational Behaviour", 66(3), 487-500.

Bell, A. S., Rajendran, D., \& Theiler, S. (2012), "Job stress, wellbeing, work-life balance and work-life conflict among Australian academics", E-Journal of Applied Psychology, 8(1): $25-37$.

Byron, K. (2005), "A meta-analytic review of work-family conflict and its antecedents", Journal of Vocational Behaviour, 67(2), 169-198.

Carlson, D. S., Kacmar, K. M., \& Williams, L. J.(2000), "Construction and Initial Validation of a Multidimensional Measure of Work-Family Conflict", Journal of Vocational Behavior, 56(2): 249-276.

Cavanaugh, M. A., Boswell, W. R., Roehling, M. V., \& Boudreau, J. W. (2000), "An empirical examination of self-reported work stress among U.S. managers", Journal of Applied Psychology, 85(1): 65-74. 
Cegarra-Leiva, D., Sánchez-Vidal, E., \& Cegarra-Navarro, J. G. (2012), "Work life balance and the retention of managers in Spanish SMEs". International Journal of Human Resource Management, 23(1): 91-108.

Chandra, V. (2012), "Work-life balance: eastern and western perspectives." International Journal of Human Resource Management, 23(5): 1040-1056.

Choi, J., Kim, A., Han, K., Ryu, S., Park, J. G., et al.(2018), "Antecedents and consequences of satisfaction with work-family balance: A moderating role of perceived insider status." Journal of Organizational Behavior, 39(1): 1-11.

Chiang, F., Birtch, T. and Kwan, H., (2010), "The moderating roles of job control and WLB practices on employee stress in the hotel and catering industry", International Journal of Hospitality Management, 29(1), 25-32.

Cogin, J. (2012), "Are generational differences in work values fact or fiction? Multi-country evidence and implications", The International Journal of Human Resource Management, 23(11): 2268-2294.

Deery, M. (2008), "Talent management, work-life balance and retention strategies." International Journal of Contemporary Hospitality Management, 20(7): 792-806.

DeVellis, R.( 2012), Scale Development Theory and Applications (3rd ed.). London: SAGE Publications, Inc.

Edwards, J. R., \& Rothbard, N. P. (2000), "Mechanism linking work and family: clarifing the relationship between work and family constructs", Academy of Management Review, 2(1): 178-199.

Frone, M., Russell, M. and Cooper, M., (1997), "Relation of work-family conflict to health outcomes: A four-year longitudinal study of employed parents". Journal of Occupational and Organizational Psychology, 70(4), 325-335.

Goddard, R., O'Brien, P. and Goddard, M., (2006), "Work environment predictors of beginning teacher burnout", British Educational Research Journal, 32(6), 857-874.

Gould-Williams, J. S., Bottomley, P., Redman, T., Snape, E., Bishop, D. J., et al. (2014), "Civic duty and employee outcomes: Do high commitment human resource practices and work overload matter?" Public Administration, 92(4): 937-953.

Grzywacz, J. G., \& Marks, N. F. (2000), " Reconceptualizing the work-family interface: An 
ecological perspective on the correlates of positive and negative spillover between work and family". Journal of Occupational Health Psychology, 5(1): 111-126.

Hammer, L. B., Cullen, J. C., Neal, M. B., Sinclair, R. R., \& Shafiro, M. V. (2005), "The Longitudinal Effects of Work-Family Conflict and Positive Spillover on Depressive Symptoms Among Dual-Earner Couples". Journal of Occupational Health Psychology, 10(2): 138-154.

Hammer, L., Kossek, E., Yragui, N., Bodner, T. and Hanson, G.(2009), "Development and Validation of a Multidimensional Measure of Family Supportive Supervisor Behaviours". Journal of Management, 35(4), 837-856.

Hill, E. J., Hawkins, A. J., Ferris, M., \& Weitzman, M.( 2001), "Finding an Extra Day a Week: The Positive Influence of Perceived Job Flexibility on Work and Family Life Balance". Family Relations, 50(1): 49-58.

Hobson, C., Delunas, L. and Kesic, D., (2001), "Compelling evidence of the need for corporate work/life balance initiatives: results from a national survey of stressful life events", Journal of Employment Counselling, 38(1), 38-44.

Homberg, F., \& Vogel, R. (2016), "Human resource management (HRM) and public service motivation (PSM): Where are we, and where do we go from here?", International Journal of Manpower, 37(5): 746-763.

Hossen, M., Begum, M., \& Zhixia, C. (2018). "Present status of organizational work-life balance practice in Bangladesh: Employees expectation and organizational arrangements", Journal of Eastern European and Central Asian Research, 5(1): 1-17.

Hsiao, H. and Mor Barak, M., (2013), "Job-related stress, social support, and work-family conflict among Mexican workers in a multinational company: A case study of a Korean-owned, US-branded former "sweatshop" in Mexico". International Journal of Social Welfare, 23(3), 309-320.

Huque, A. S. (2011), "Some neglected aspects of performance in field administration in Bangladesh". International Journal of Public Administration, 34(5): 318-328.

Hussain, A., \& Endut, N. (2018),"Do decent working conditions contribute to work - life balance A study of small enterprises in Bangladesh". Asia Pacific Journal of INnovation and Entrepreneurship,12(1): 90-104. 
Jacobs, C., (2009), "How to bring about change in the Bangladesh civil service? Attempts to change mindsets, behaviours and practice", Public Administration and Development, 29(3), 218-227.

Jesmin, S. S., \& Seward, R. R. (2011), "Parental leave and fathers' involvement with children in Bangladesh: A comparison with United States", Journal of Comparative Family Studies, 42(1): 95-112.

Kirby, E. and Krone, K., (2002), "The policy exists but you can't really use it": communication and the structuration of work-family policies". Journal of Applied Communication Research, 30(1), 50-77.

Kossek, E., Pichler, S., Bonder, T. and Hammer, L., (2011), "Workplace social support and work-family conflict: a meta-analysis clarifying the influence of general and work family-specific supervisor and organizational support". Personnel Psychology, 64(2), 289-313.

Kossek, E. and Nichol, V., (2006), "The Effects of on-site child care on employee attitudes and performance", Personnel Psychology, 45(3), 485-509.

Kulik, L., Shilo-Levin, S., \& Liberman, G. (2015), "Multiple Roles, Role Conflict, and Sense of Meaning in Life Among Working Parents", Journal of Career Development, 42(4): 263-280.

Ladd, D. and Henry, R., (2000), "Helping Coworkers and Helping the Organization: The Role of Support Perceptions, Exchange Ideology, and Conscientiousness", Journal of Applied Social Psychology, 30(10), 2028-2049.

Leavy, R., (1983), "Social support and psychological disorder: A review", Journal of Community Psychology, 11(1), 3-21.

Lewis, S., Gambles, R., \& Rapoport, R. (2007), "The constraints of a "work-life balance" approach: An international perspective", International Journal of Human Resource Management, 18(3): 360-373.

Major, V., Klein, K. and Ehrhart, M., (2002), "Work time, work interference with family, and psychological distress". Journal of Applied Psychology, 87(3), 427-436.

Mauno, S., \& Kinnunen, U. (1999), "The effects of job stressors on marital satisfaction in Finnish dual-earner couples". Journal of Organizational Behaviour, 20(6): 879-895. 
McHugh, M., \& Brennan, S. (1994), "Managing the Stress of Change in the Public Sector", International Journal of Public Sector Management, 7(5): 29.

Meyer, J., Allen, N., \& Smith, C. (1993), "Commitment to organizations and occupationsExtension and test of a three-component conceptualization". Journal of Applied Psychology, 78(4): 538-551.

Nunnally, J. C. (1978). Psychometric theory (2 ${ }^{\text {nd }}$ ed.). New York: McGraw-Hill.

Porter, L. W., Steers, R. M., Mowday, R. T., \& Boulian, P. V. (1974), "Organizational commitment, job satisfaction, and turnover among psychiatric technicians", Journal of Applied Psychology, 59(5): 603-609.

Roberts, K. (2007), "Work-life balance - the sources of the contemporary problem and the probable outcomes". Employee Relations, 29(4): 334-351.

Shinn, M., Wong, N., Simko, P. and Ortiz-Torres, B., (1989), "Promoting the well-being of working parents: Coping, social support, and flexible job schedules". American Journal of Community Psychology, 17(1), 31-55.

Siddiquee, N. A. (2003), "Human resource management in Bangladesh civil service: constraints and contradictions". International Journal of Public Administration, 26(1): $35-60$.

Smith, J., \& Gardner, D. (2007), "Factors effecting employee use of work-life balance initiatives" . New Zealand Journal of Psychology, 36(1): 3-12.

Stanton, J. M., Balzer, W. K., Smith, P. C., Parra, L. F., \& Ironson, G. (2001), " A General Measure of Work Stress: The Stress in General Scale", Educational and Psychological Measurement, 61(5): 866-888.

Sung Kim, J., \& Ryu, S. (2017), "Employee satisfaction with work-life balance policies and organizational commitment: A Philippine study". Public Administration and Development, Dev.(37): 260-276.

Tasnim, M., Hossain, M. Z., \& Enam, F. (2017), "Work-life balance : Reality check for the working women of Bangladesh". Journal of Human Resource and Sustainability Studies, 2017(5): 75-86.

Thomas, L. and Ganster, D., (1995), "Impact of family-supportive work variables on work family conflict and strain: A control perspective", Journal of Applied Psychology, 80(1), 6-15. 
Thompson, C. and Prottas, D., (2006), "Relationships among organizational family support, job autonomy, perceived control, and employee well-being", Journal of Occupational Health Psychology, 11(1), 100-118.

Uddin, M. M. and Chowdhury M. M., (2015), "An Investigation into issues of WLB of women entrepreneurs in Bangladesh", Journal of Business and management, 17(4), 07-17.

United Nations Development Programme (UNDP), (2012), "Gender equality and women's empowerment in public administration, Bangladesh case study". available at: : https://www.undp.org/content/undp/en/home/librarypage/democratic governance/public administration/gepa2.html (accessed $6^{\text {th }}$ May, 2018)

Wayne, J. H., Casper, W. J., \& Allen, T. D. (2017), "In search of blance: a conceptual and empirical integration of multiple meanings of work-family balance". Personnel Psychology, 2017(70): 167-210.

White, M., Hill, S., McGovern, P., Mills, C., \& Smeaton, D. (2003), "High-performance Management Practices, Working Hours and Work-Life Balance". British Journal of Industrial Relations, 41(2): 175-195. 
Table 1: Descriptive information

\begin{tabular}{|c|c|c|c|c|c|c|c|c|c|c|c|}
\hline & Mean & SD & 1 & 2 & 3 & 4 & 5 & 6 & 7 & 8 & 9 \\
\hline 1. Age & 34.69 & 3.05 & & & & & & & & & \\
\hline 2. Tenure & 1.91 & 0.52 & $.50 * *$ & & & & & & & & \\
\hline 3. Gender ${ }^{a}$ & 0.81 & 0.39 & 0.12 & 0.14 & & & & & & & \\
\hline \multicolumn{12}{|l|}{ 4. Married with kids under 18} \\
\hline years old ${ }^{b}$ & 0.77 & 0.42 & $.37 * *$ & 0.08 & -0.11 & & & & & & \\
\hline 5. Job stress & 4.15 & 0.43 & -0.01 & 0.04 & 0.08 & 0.03 & & & & & \\
\hline \multicolumn{12}{|c|}{ 6. Family supportive organization } \\
\hline policy & 2.50 & 0.71 & 0.13 & 0.09 & -0.07 & -0.01 & $-.28 * *$ & & & & \\
\hline \multicolumn{12}{|c|}{ 7. Family supportive supervisors' } \\
\hline behaviour & 2.55 & 0.79 & 0.07 & -0.01 & -0.13 & -0.07 & $-.34 * *$ & $.76^{* *}$ & & & \\
\hline \multicolumn{12}{|c|}{ 8. Family supportive co-workers' } \\
\hline behaviour & 2.84 & 0.79 & 0.02 & -0.10 & 0.11 & 0.01 & $-.17^{*}$ & $.50 * *$ & $.55^{* *}$ & & \\
\hline 9. Work-life balance & 2.17 & 0.72 & 0.14 & 0.12 & $-.17^{*}$ & -0.10 & $-.47^{* *}$ & $.43^{* *}$ & $.42 * *$ & $.20^{*}$ & \\
\hline 10. Affective commitment & 3.47 & 0.56 & -0.11 & -0.01 & 0.02 & -0.14 & -0.09 & $.19 *$ & $.31 * *$ & $.21 * *$ & 0.11 \\
\hline
\end{tabular}

Note: $\mathrm{N}=157$. $* * \mathrm{P}<0.01 ; * \mathrm{P}<0.05$

${ }^{\text {a }} 0=$ female $; 1=$ male

${ }^{\mathrm{b}} 0=$ others; $1=$ married with kids under 18 years old 
Table 2: Regression result

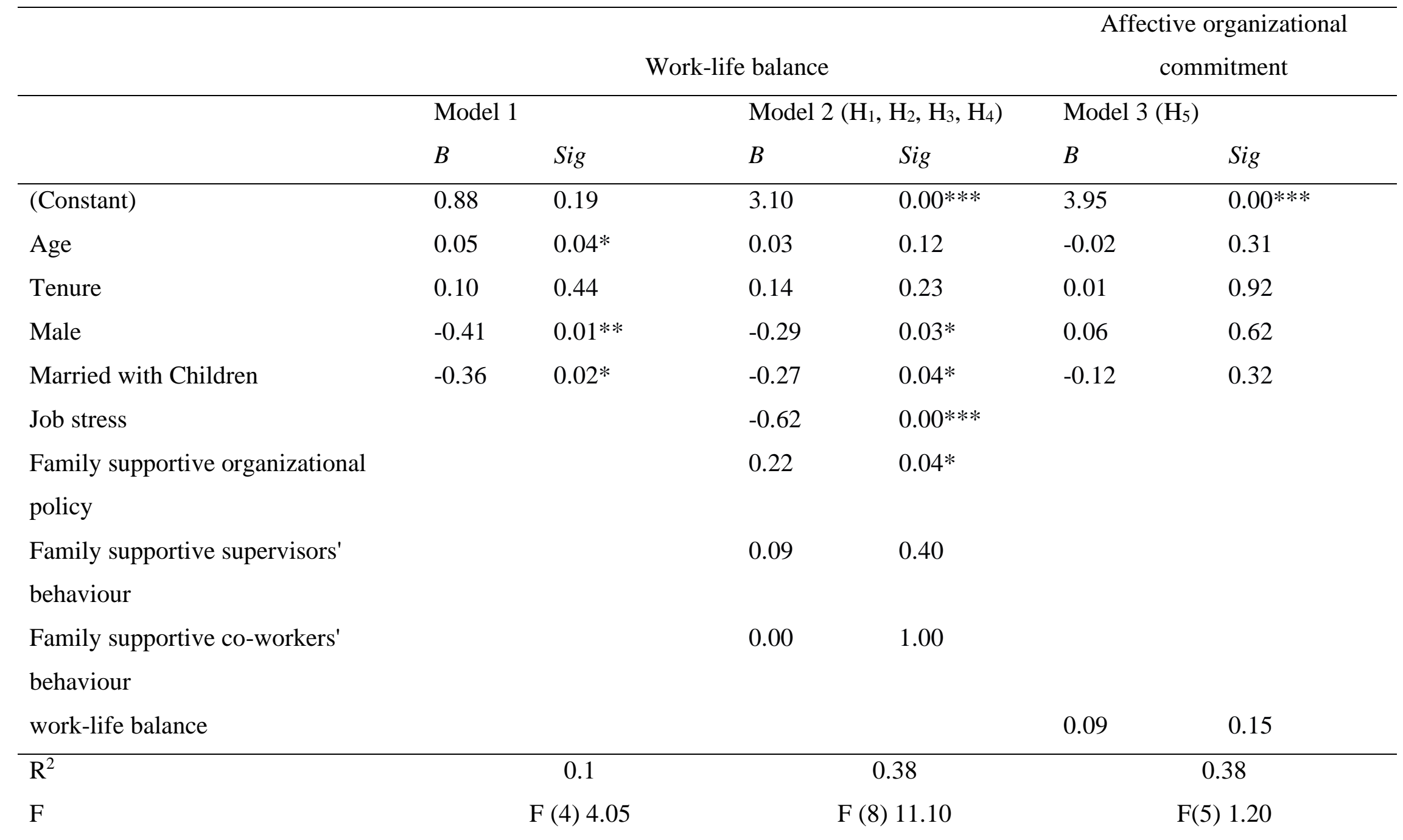

Note: $\mathrm{N}=157$; unstandardized coefficients are reported; $* * * \mathrm{p}<0.001 * * \mathrm{P}<0.01 ; * \mathrm{P}<0.05$ 
Figure 1: Administrative Structure of Bangladesh

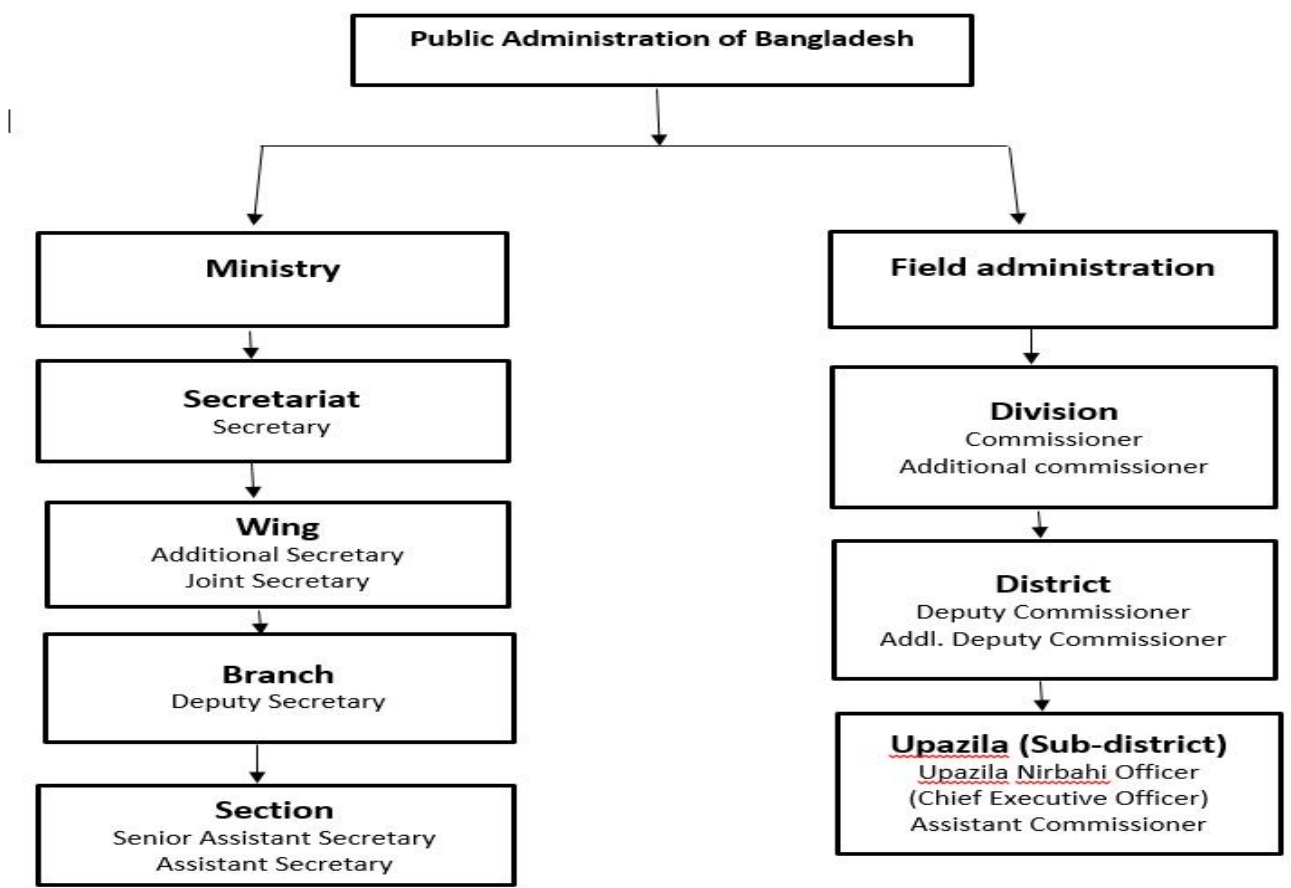

Source: Organogram of Ministry of Public Administration, MOPA (2017) 
Figure 2: Theoretical Framework

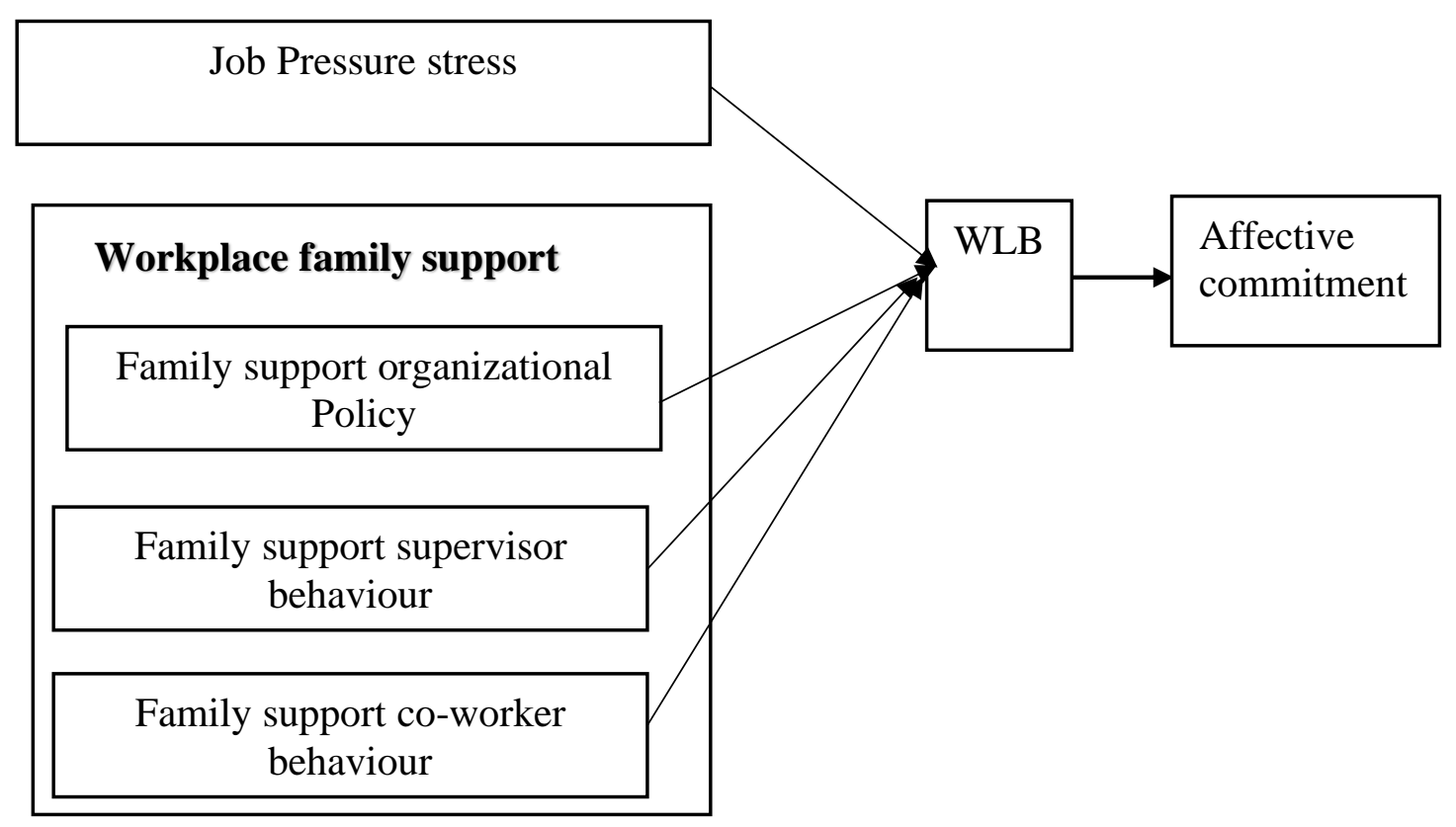

